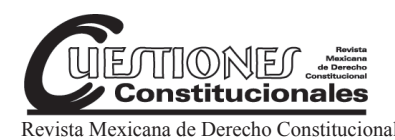

Núm. 37, julio-diciembre 2017

\title{
¿UNA NUEVA CONSTITUCIÓN PARA MÉXICO? NOTAS A LA LUZ DE UN DEBATE
}

\section{María Paloma Biglino CAMPOS*}

Queda lejos de mis posibilidades opinar, con algún fundamento, acerca de la conveniencia de una nueva norma fundamental para este país. El trabajo del profesor Edgar Corzo, acerca de ¿Una nueva Constitución para México en el 2017? ${ }^{1}$ incita, sin embargo, a realizar algunas consideraciones de teoría general que pueden aplicarse también a la propuesta que se formula en dicho texto.

El concepto racional-normativo de Constitución no sólo impone que la norma fundamental tenga un contenido determinado, es decir, el reconocimiento de los derechos fundamentales y de la división de poderes. Conlleva, entre otros requisitos, la exigencia de que la norma suprema sea manifestación de un poder constituyente externo al propio aparato estatal. En un sistema democrático, la fuerza de la Constitución ya no puede edificarse, al modo de H. Kelsen, sobre criterios puramente formales, que fundamentan la fuerza de la norma superior en su capacidad de determinar la manera en que han de elaborarse las inferiores. En la actualidad, la Constitución es norma de las normas por ser manifestación directa de la voluntad popular. Esta idea, nuclear y ampliamente reconocida, implica exigencias que afectan al cambio constitucional. Para el tema que se analiza, dichas condiciones pueden resumirse en cuatro ideas:

I. Al margen de respetar los requisitos procedimentales establecidos en el texto en vigor, la elaboración de una nueva Constitución exige poner en

\footnotetext{
* Catedrática de Derecho constitucional, Universidad de Valladolid (España).

1 Corzo Sosa, Edgar, Prólogo, en Pinto Muñoz, Jacinto Héctor, Una nueva Constitución aprobada por el pueblo soberano, UNAM, Instituto de Investigaciones Jurídicas, 2016, pp. XIII-XX.
} 
Esta revista forma parte del acervo de la Biblioteca Jurídica Virtual del Instituto de Investigaciones Jurídicas de la UNAM

acto el poder constituyente del pueblo. En los sistemas democráticos contemporáneos, que son eminentemente representativos, esto no impide que la nueva Constitución sea redactada por delegados democráticamente elegidos, impone, más bien, que sea aprobada por los ciudadanos en referéndum; es esta participación el factor que legitima la Constitución y, sobre todo, propicia la sumisión del legislador (que es poder constituido) a la norma fundamental derivada del poder originario del pueblo.

II. Un referéndum para la aprobación de la Constitución representa, además, el camino más eficaz para propiciar el consenso, porque cuanto mayores sean los acuerdos entre las fuerzas políticas y más abierto sea el texto constitucional, más elevado será el número de personas que se sentirán identificadas con la nueva norma. Una votación popular no sólo incrementa la legitimidad de la Constitución, sino que también limita la posibilidad de que la norma fundamental sea únicamente la expresión de la ideología de la mayoría.

Siempre es conveniente que la Constitución tenga vocación de perdurabilidad porque, aunque sea necesario prever su capacidad de adaptación a las transformaciones que experimenta la realidad, tiene que fijar los valores, principios y reglas que fundamentan la existencia de la comunidad que la ha creado. La historia del continente europeo y del latinoamericano demuestra la escasa vigencia y la inestabilidad política que originaron normas fundamentales que impusieron a la minoría los puntos de vista de la mayoría. Por tal razón, la Constitución debe quedar al margen de los programas electorales, ya que éstos se elaboran y publicitan en el ámbito de una contienda, donde lo que se pretende no es convencer o compartir puntos de vista con el adversario, sino derrotarlo. Y nada más alejado del ambiente político que requiere la aprobación o modificación constitucional.

III. Viniendo de otro país resulta difícil opinar sobre la alternativa de modificar la Constitución en vigor o elaborar una de nueva planta. Creo, además, que cualquiera de estas dos alternativas no debe ser el punto de partida, sino el de llegada; es decir, ante cualquier cambio constitucional y en cualquier sistema jurídico, lo primero que debería hacerse es empezar por concretar qué es lo que funciona mal en el sistema jurídico. Es posible, en efecto, que muchos de los cambios puedan introducirse por medio de la legislación ordinaria o con breves retoques de la norma fundamental. En otras ocasiones, quizá, la Constitución necesita modificaciones más intensas, o cuando no, una redacción de nueva planta. A la hora de inclinarse por esta última alternativa influyen, sin duda, razones de carácter político. Pero 
Esta revista forma parte del acervo de la Biblioteca Jurídica Virtual del Instituto de Investigaciones Jurídicas de la UNAM

la necesidad de un cambio tan sustancial tiene que fundamentarse también en sólidas razones de carácter técnico.

IV. Si, como es sabido, la Constitución es una decisión en la que el poder constituyente del pueblo decide porqué, para qué y cómo se ejerce el poder, es necesario que sea fácilmente accesible para los ciudadanos. Además, la conveniencia de elaborar textos abiertos, con los que pueda identificarse la mayoría de las personas, aconseja reunir en la norma fundamental únicamente las reglas principales que regulan la estructura y funcionamiento de las instituciones, así como los derechos y libertades de las personas con relación al poder.

De no ser así, esto es, cuando la Constitución se convierte en un código demasiado detallista, se corren varios riesgos. El principal de todos ellos es limitar excesivamente el ámbito de libertad del legislador ordinario, que es quien expresa de forma ordinaria la soberanía popular y manifiesta la voluntad de la mayoría. Es verdad que la Constitución debe ser una norma de consenso, pero dicho acuerdo ha de ceñirse a establecer las bases fundamentales del sistema. El Parlamento debe disponer, pues, de espacio suficiente para poder llevar a cabo sus propias políticas sin tener que modificar la norma fundamental para ello. 